\title{
GENETIC VARIATION OF PALIURUS RAMOSISSIMUS (LOUR.) POIRET (RHAMNACEAE): IMPLICATION FOR CONSERVATION STRATEGIES
}

\author{
LEE, S. H. - CHAE, H. M. - CHA, S. S. - SHIM, J. K.* \\ Department of Life Science, Chung-Ang University, Seoul 156-756, Korea \\ (phone: +82-2-820-5211; fax: +82-2-825-5206) \\ *Corresponding author \\ e-mail:shimjk@cau.ac.kr \\ (Received $26^{\text {th }}$ Sep 2016; accepted $26^{\text {th }}$ Nov 2016)
}

\begin{abstract}
Paliurus ramosissimus (Rhamnaceae) is a deciduous shrub found on the seashore of Jeju Island, located at the southern tip of the Korean peninsula, and has been designated a rare plant species by the Korea Forest Service. Random amplified polymorphic DNA was used to investigate the genetic variation within and among $P$. ramosissimus populations on Jeju Island. Populations of $P$. ramosissimus showed a relatively low genetic diversity. The percentage of polymorphic bands (PPB) ranged from $33.3 \%$ to $63.6 \%$ (average $=51.4 \%$ ), Shannon's information index $(I)$ ranged from 0.213 to 0.352 (average $=0.316$ ), and Nei's gene diversity $(H)$ ranged from 0.149 to 0.239 (average $=0.218$ ). Analysis of molecular variance and Nei's gene differentiation coefficient showed low genetic differentiation among populations $(\Phi s t=0.207$ and $G s t=0.186)$. The level of gene flow was sufficient to counter population divergence due to genetic drift $(\mathrm{Nm}=0.109)$. Population genetic information obtained from this study could provide a valuable baseline for conservation and management plans for this species; $P$. ramosissimus on Jeju Island have to be protected through in situ conservation. The populations Pyo-sun and Il-gwua with high genetic diversity have conservation priority. In particular, Pyo-sun population protection must be the highest priority, as this population was revealed to have a high genetic diversity despite its small size.
\end{abstract}

Keywords: genetic diversity, genetic differentiation, plant conservation, RAPD, Jeju Island

\section{Introduction}

Genetic variation provides the resources on which populations draw from to survive drastic environmental changes and for evolutionary adaptation (Li et al., 2013; Zhang et al., 2012; Frankham et al., 2002; Ellstrand and Elam, 1993; Milligan et al., 1994; Tansley and Brown, 2000). Species that have adapted to local environments or have been isolated for long periods are easily affected adversely by small environmental changes because they have low levels of genetic variation (Tansley and Brown, 2000; Hamrick and Godt, 1989; Frankham, 1996). Therefore, the level of genetic variation suggests that the geographical history and the circumstances that the taxon faced could provide the basic information to maintain genetic variation (Frankham et al., 2002) or to establish effective conservation strategies (Yu et al., 2011; Fritsch and Rieseverg, 1996) for target species.

Paliurus ramosissimus (Lour.) Poiret (Rhamnaceae) is a deciduous shrub found only on the Jeju Island in Korea (Lee, 2003). The geographical distribution of this species has been acknowledged in Taiwan, Japan, China, Vietnam, and other tropical and subtropical Asian locations (Nakanish, 1981, Chang and Kim, 2001). Jeju Island is known as the northern distributional limit of P. ramosissimus (Kim et al., 2002). The habitats of $P$. ramosissimus are situated above the high-water level on the shores and estuaries (Nakanish, 1981). The fruit of this species has a corky or woody mesocarp and 
is disseminated by seawater (Nakanish, 1981). Owing to its rarity, P. ramosissimus was listed as an endangered species in 2005 by the Ministry of Environment of Korea (Ministry of Environment, 2005). However, this species was lifted from the list in 2011, in accordance with newly discovered habitats and estimations of stable populations (Ministry of Environment, 2012). Nevertheless, this species is still listed on the rare plant list of the Korea Forest Service because of its small population size (Korea National Arboretum, 2009).

The habitat distribution of $P$. ramosissimus on Jeju Island, and population size and vegetation composition of $P$. ramosissimus have been studied in recent years (Chang and Kim, 2001; Kim et al., 2007; Kim, 2006). Nakanish et al., (2004), surveyed the natural habitat distribution and vegetation structure of $P$. ramosissimus on Jeju Island and compared the characteristics between habitats in Korea and Japan. However, molecular population genetic studies on $P$. ramosissimus have not been performed until now.

Molecular markers have been widely used to characterize the genetic structure of plant populations (Liu et al., 2012). The random amplified polymorphic DNA (RAPD) method has some advantages, such as the high polymorphism generation and the fact that it does not require previous knowledge of the genome. Therefore, it is now widely appreciated that understanding patterns of genetic variation is of critical importance to the conservation of threatened species (Trindade et al., 2009). In addition, molecular approaches are providing particularly valuable resources to fingerprint the consequences of historical events such as range expansion, fragmentation, and bottlenecks in population size (Haig, 1998), which may have significant implications to the development of conservation strategies (Newton et al., 1999).

RAPD markers were used to assess genetic diversity and genetic variation of the different $P$. ramosissimus populations in this study. The main objectives of this study were to (1) assess levels of genetic diversity of the natural populations; (2) reveal the partitioning of the genetic variations within and among populations; (3) provide elementary information for the conservation of $P$. ramosissimus.

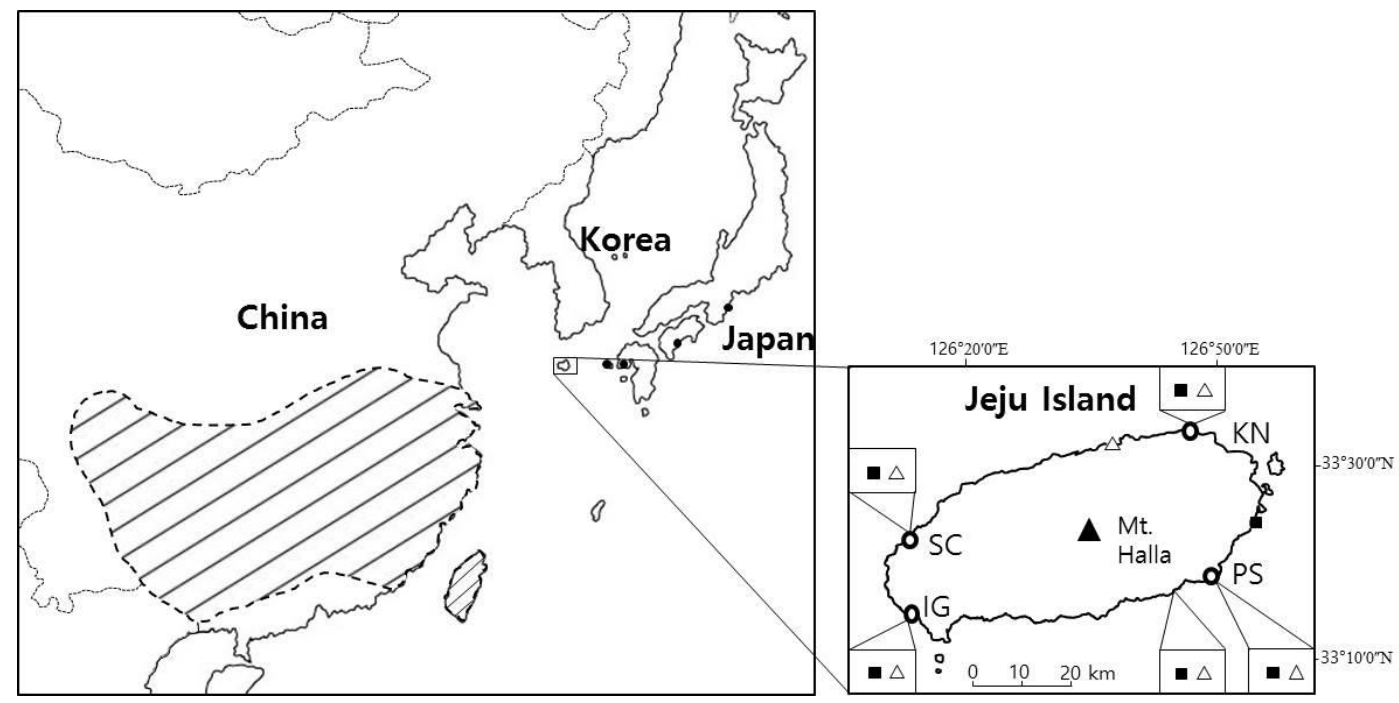

Figure 1. Geographical distribution of P. ramosissimus. P. ramosissimus in southern parts of China, Taiwan (hatched area, from Chang et al. (2005), and southern parts of Japan (closed circle, Nakanishi 1981). The plant community studies on the P. ramosissimus on Jeju Island performed by Nakanishi (2004), closed squares, and Kim (2006), open triangles. Opened circles are sampled populations in this study. KN, Kim-nyung; PS, Pyo-sun; IG, Il-gwua; SC, Sin-chang. 
Table 1. The location of populations and sample size of surveyed of $P$. ramosissimus populations on Jeju Island, Korea ( $n=$ sample size; $N=$ population size).

\begin{tabular}{cclccc}
\hline No. & Population & Latitude & Longitude & n & N \\
\hline 1 & Kim-nyung (KN) & $33^{\circ} 33^{\prime} 49.7^{\prime \prime}$ & $126^{\circ} 45^{\prime} 53.8^{\prime \prime}$ & 18 & 30 \\
2 & Pyo-sun (PS) & $33^{\circ} 18^{\prime} 54.9^{\prime \prime}$ & $126^{\circ} 50^{\prime} 17.9^{\prime \prime}$ & 16 & 30 \\
3 & Il-gwua (IG) & $33^{\circ} 14^{\prime} 27.0^{\prime \prime}$ & $126^{\circ} 13^{\prime} 37.2^{\prime \prime}$ & 34 & 130 \\
4 & Sin-chang (SC) & $33^{\circ} 20^{\prime} 341^{\prime \prime}$ & $126^{\circ} 10^{\prime} 30.3^{\prime \prime}$ & 17 & 40 \\
\hline
\end{tabular}

Abbreviations of populations are in the parenthesis.

\section{Materials and Methods}

\section{Plant sampling and DNA extraction}

Eighty-five individuals from four populations of $P$. ramosissimus were collected from Jeju Island, which is the largest southern end island in Korea (Fig. 1; Table 1). For molecular analysis, two or three young and healthy leaflets were collected from each individual shrub of $P$. ramosissimus. The individual shrub samples were collected about $5 \mathrm{~m}$ away each other in a population, and the sampled leaves were put into an individual vinyl bag with solid moisture absorbent in the field. The leaf samples were preserved in the lab at $-20^{\circ} \mathrm{C}$ until DNA extraction.

The frozen leaf samples were ground for DNA extraction, using mortar and pestle, in liquid nitrogen. DNA was extracted using the DNeasy ${ }^{\circledR}$ Plant mini kit (Qiagen, Almeda, CA, USA). The extracted DNA concentration was adjusted to $25 \mathrm{ng} / \mu \mathrm{l}$ for RAPD PCR.

\section{RAPD PCR}

Fifty primers were screened using Operon RAPD ${ }^{\circledR}$ 10-mer kit (Quiagen Operon Technologies) and five primers were selected based on their reproducible and distinct banding patterns (Table 1). DNA amplification was performed in a 20 - $\mu 1$ reaction, containing 1U Taq DNA polymerase (Takara bio Inc., Japan), $1.0 \mu$ template DNA (25 ng genomic DNA), $2.0 \mu 1$ 10X PCR buffer, $2.0 \mu 1$ primer $(20$ pmol $), 1.0 \mu 1 \mathrm{dNTPs}$ mixture (2.5 mM each). Amplifications were conducted in $\mathrm{T}$ professional basic (Biometra, Goettingen, German). Amplification cycles were as follows: initial denaturation at $94^{\circ} \mathrm{C}$ for $2 \mathrm{~min}$, followed by 39 cycles of $30 \mathrm{sec}$ at $94^{\circ} \mathrm{C}$ (denaturation), $30 \mathrm{sec}$ at $36^{\circ} \mathrm{C}$ (annealing), and $1 \mathrm{~min}$ at $72^{\circ} \mathrm{C}$ (extension), with a final extension at $72^{\circ} \mathrm{C}$ for $10 \mathrm{~min}$. The PCR products were electrophoresed on $1.4 \%$ agarose gel in 0.5 for $10 \mathrm{~min}$, and stained with ethidium bromide. The gels were viewed and photographed with Gel Doc 2000 (Bio Rad Laboratory Inc., California, USA) gel imaging system.

\section{Data analysis}

Each RAPD fragment was scored as " 1 " if present or " 0 " if absent, and was made into a binary data matrix. The data matrix was analyzed using POPGENE 1.32 (Yeh and Boyle, 1997) to assess genetic parameters: percentage of polymorphic band (PPB) for the total bands, observed number of alleles $(A o)$, Effective number of alleles $(A e)$, Nei's (1973) gene diversity $(H)$, Shannon's information index $(I)$, coefficient of gene differentiation $(G s t)$, and Nei's unbiased genetic identity and genetic distance.

Analysis of molecular variance (AMOVA) was carried out to describe the genetic differentiation among populations of $P$. ramosissimus using AELEQUIN ver. 3.0 (Excoffier et al., 2005). The significance of $\Phi$ st ( $F$-statistic analogue, Ge et al., 2005), 
calculated by AMOVA, was tested by 1000 permutations. The level of gene flow, the proportion of new immigrant genes moving into a population, was determined using the formula: $N m=1 / 4(1-G$ st) $/ G$ st (Slatkin and Barton, 1989), where $N$ is population effective size and $m$ is migration rate.

To illustrate the genetic relationships between populations, we analyzed the matrix of RAPD bands with UPGMA (Unweighted pair-group method with arithmetic average) cluster analysis using POPGENE 1.32.

A principal coordinate analysis (PCoA) was performed by plotting Euclidian distance on 3-dimensional space, calculated based on a binary matrix of RAPD band pattern for all pair-wise individuals of experimental $P$. ramosissimus, by using GenAlex 6.5 (Peakall and Smouse, 2006).

\section{Results}

\section{Genetic diversity}

Fifty primers were screened, of which five primers showed reliable banding patterns. The five primers generated 31 clear and repeatable bands among 85 individuals. The average number of bands per primer was 6.6 (Table 2). At the species level, 26 of 33 bands showed polymorphic loci, and $78.8 \%$ polymorphism. The percentage of polymorphic bands (PPB) for a population ranged from $33.3 \%$ to $63.6 \%$, and the mean percentage of polymorphic bands of all four populations was $53.8 \%$ (Table 3).

Table 2. Primer sequences and amplified products of RAPD markers for the four P. ramosissimus on Jeju Island in Korea.

\begin{tabular}{cccc}
\hline Primer & Sequence (3'-5') & No. of loci & No. of polymorphic loci \\
\hline OPA-10 & GTGATCGCAG & 7 & 6 \\
OPA-17 & GACCGCTTGT & 6 & 4 \\
OPAF-07 & GGAAAGCGTC & 6 & 6 \\
OPP-14 & CCAGCCGAAC & 8 & 5 \\
OPP-11 & AACGCGTCGG & 6 & 5 \\
Mean & & 6.6 & 3.9 \\
\hline
\end{tabular}

Table 3. The genetic variations revealed through RAPD markers among populations of $P$. ramosissimus on Jeju Island in Korea. Population abbreviations are shown in Table 1 and Figure 1. (PPB $=$ Percentage of polymorphic band; Ao=Observed number of alleles; $A e=$ Effective number of alleles; $H=N e i$ 's gene diversity; I=Shannon's information index).

\begin{tabular}{cccccc}
\hline Populations & PPB & $\boldsymbol{A e}$ & $\boldsymbol{A o}$ & $\boldsymbol{H}$ & $\boldsymbol{I}$ \\
\hline KN & 54.6 & 1.3903 & 1.5455 & 0.217 & 0.314 \\
SC & 33.3 & 1.2722 & 1.3333 & 0.149 & 0.213 \\
PS & 63.6 & 1.4862 & 1.6364 & 0.266 & 0.383 \\
IG & 63.6 & 1.4093 & 1.6364 & 0.239 & 0.352 \\
Average & 53.8 & 1.3895 & 1.5379 & 0.218 & 0.316 \\
Total & 78.8 & 1.4482 & 1.7879 & 0.264 & 0.398 \\
\hline
\end{tabular}

The IG and PS populations have high genetic diversity indices ( $\mathrm{PPB}=63.6$ and 63.6; $A e=1.4093$ and 1.4862; $A o=1.6364$ and 1.6364; $H=0.239$ and $0.266 ; I=0.352$ and 0.383 , respectively). On the other hand, SC and $\mathrm{KN}$ populations, which are on the northern shoreline of Jeju Island, exhibited lower genetic diversity than the southern shoreline of 
PS and IG. The genetic diversity indices at species level were higher than the average population diversity values, which showed the highest values of diversity among tested populations, 78.8 of PPB, 0.264 of $H$, and 0.398 of I (Table 3).

\section{Genetic structure}

The coefficient of genetic differentiation between populations $(G$ st) was 0.186 , as estimated by partitioning of the total gene diversity. The level of gene flow $(\mathrm{Nm})$ was estimated to be 1.094 per individual per generation between populations. Similarly to Nei's genetic diversity statistics, analysis of molecular variance (AMOVA) made using RAPD data showed that $79.3 \%$ of the total genetic variability can account for the differences within populations of $P$. ramosissimus. The remaining $20.7 \%$ variations are due to variations among populations $(P<0.001)$ (Table 4$)$.

Table 4. Analysis of molecular variance for populations of P. ramosissimus on Jeju Island in Korea.

\begin{tabular}{ccccc}
\hline $\begin{array}{c}\text { Source of } \\
\text { variance }\end{array}$ & d.f. & $\begin{array}{c}\text { Variance } \\
\text { components }\end{array}$ & \% of total variance & $\boldsymbol{P}$-value \\
\hline $\begin{array}{c}\text { Among } \\
\text { Populations }\end{array}$ & 3 & 50.99 & 20.7 & $<0.001$ \\
Within & 81 & 217.44 & 79.3 & \\
Population & & & \\
\hline
\end{tabular}

A UPGMA dendrogram was made by using Nei's genetic distances among population (Fig. 2). Each population showed very near genetic relationships. The populations grouped below the 0.118 genetic distances between PS and SC (Table 5). This result means that the four populations show low genetic differentiation although KN, SC, IG grouped to one clade excluding PS. The populations of IG and PS, which are located at the southern coast, have relatively high genetic diversity. However, the two populations showed greater genetic distance, although at low levels, and IG showed the largest population size and short genetic distances between $\mathrm{KN}$ and $\mathrm{SC}$ in the northern shoreline. Therefore the IG population and PS population are important in the genetic relationships between P. ramosissimus populations on Jeju Island.

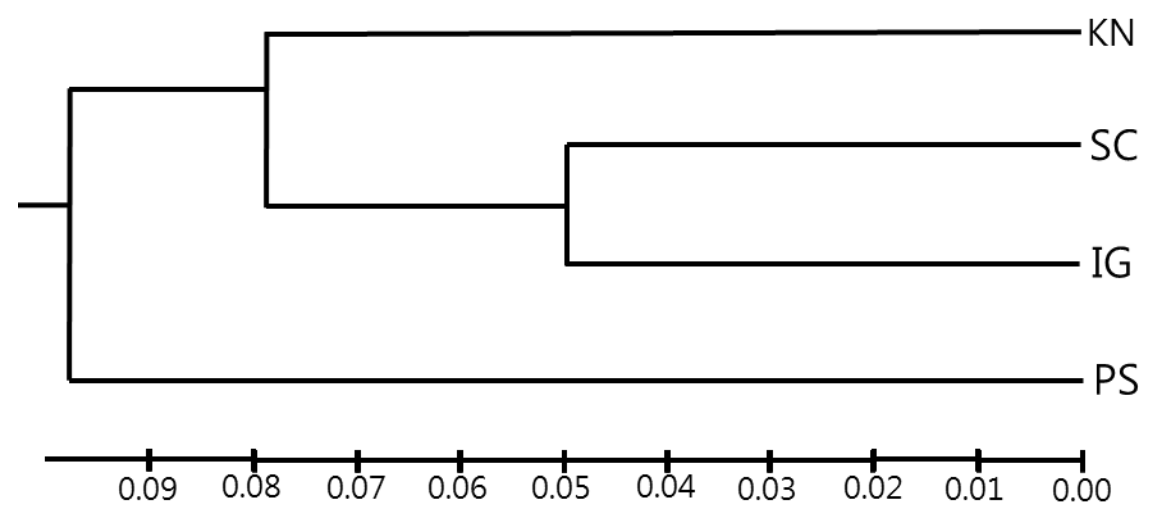

Figure 2. UPGMA dendrogram of the four P. ramosissimus populations on Jeju Island. The scale bar represents Nei's genetic distance. Population abbreviations are shown in Table 1 and Figure 1. 
Table 5. Genetic identities (above diagonal) and Nei's genetic distance (below diagonal), using RAPD markers between four populations of P. ramosissimus on Jeju Island in Korea. Population abbreviations are shown in Table 1 and Figure 1.

\begin{tabular}{ccccc}
\hline Population & KN & SC & PS & IG \\
\hline KN & $* * * *$ & 0.9117 & 0.9029 & 0.9420 \\
SC & 0.0925 & $* * * *$ & 0.8892 & 0.9521 \\
PS & 0.1021 & 0.1175 & $* * * *$ & 0.9394 \\
IG & 0.0598 & 0.0491 & 0.0625 & $* * * *$ \\
\hline
\end{tabular}

RAPD banding pattern of each $P$. ramosissimus population on the PCoA analysis also did not show clear separation between populations with most of bands overlapped (Fig. $3)$. Axis one and axis two exhibit $17.51 \%$ and $17.05 \%$ of interpretabilities, respectively.

Principal Coordinates (PCOA)

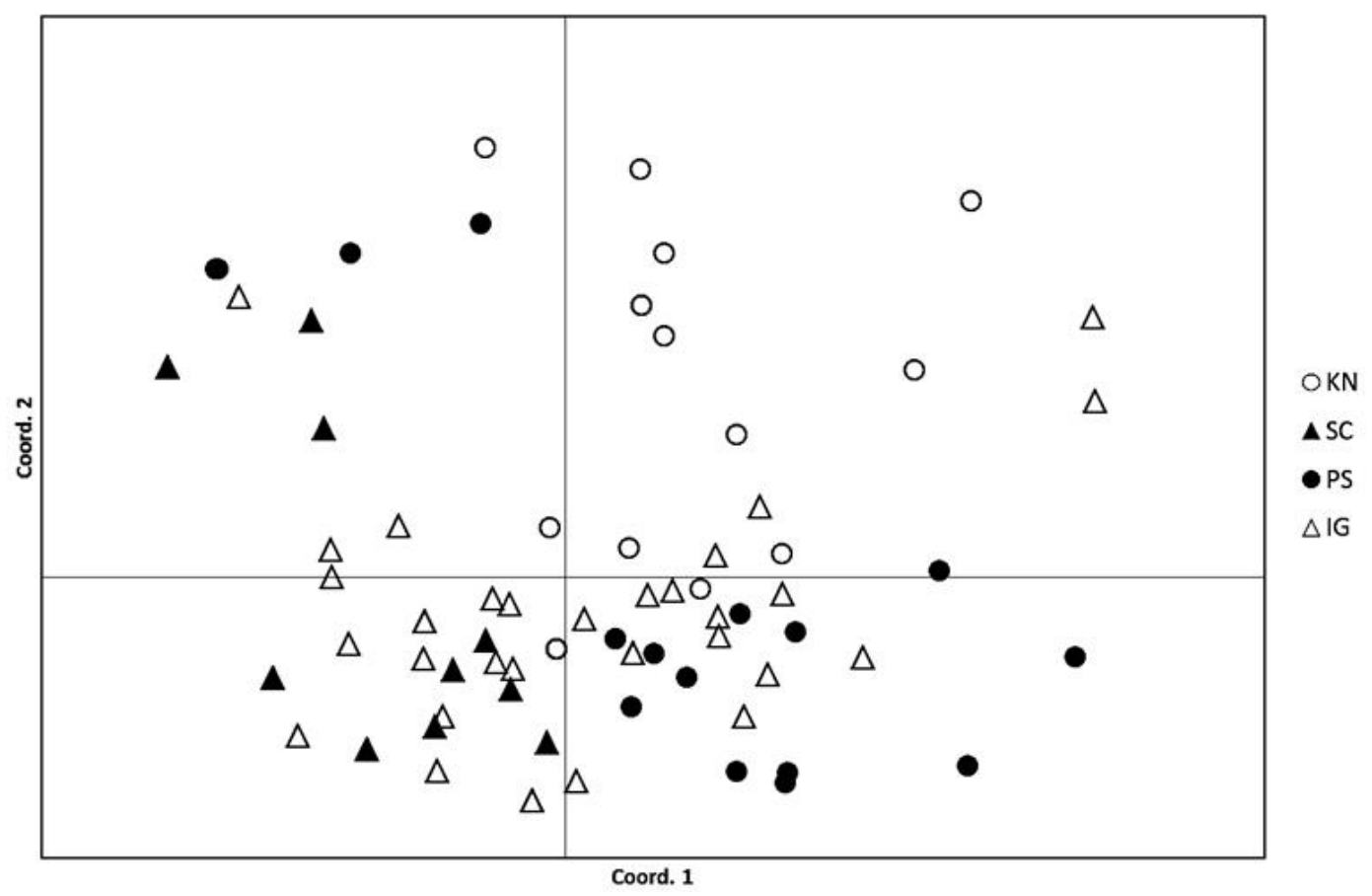

Figure 3. Principal coordinates analysis (PCoA) plot for 85 individuals from four $P$. ramosissimus populations on Jeju Island in Korea based on RAPD markers. Population abbreviations are shown in Table 1 and Figure 1.

\section{Discussion}

\section{Genetic diversity}

Genetic diversity depends on the regional distribution extent, the size of the population, breeding system, seed dispersal, and the life history traits of the species (Hamrick et al., 1992). In plant species, the breeding system is the most important major factor in explaining genetic variability at the population level (Ellstrand and Elam, 1993; Nybom, 2004). In general, self-fertilizing taxa tend to be the least diverse, whereas the outcrossing taxa tend to be the most diverse. 
Genetic diversity of $P$. ramosissimus-based RAPD markers on Jeju Island showed slightly low genetic variation at the population level. The Nei's diversity at population level of $P$. ramosissimus $(H=0.217)$ was lower than that of the average long-lived perennial plants, $H=0.25$, and also lower than that of the average outcrossing species $(H=0.27)$ but higher than that of selfing $(H=0.12)$ and mixed $(H=0.18)$ species (Nybom, 2004).

P. ramosissimus is the one species of Rhamnaceae assumed to be outcrossing. Bolmgren and Oxelman (2004), Meden and Bailio (2001), and Meden (1994) had indicated that most species in the family Rhamnaceae show the outcrossing breeding system. When we assume that $P$. ramosissimus is the one outcrossing species, the genetic diversity $H=0.217$ on Jeju Island is relatively low genetic variation.

In general, population size and within-population genetic diversity shows a positive relationship (Chang et al., 2005; Frankham et al., 2002), however, population PS showed high genetic diversity although it has a small population size. On the other hand, population IG showed high genetic diversity with the largest population size.

Comparing the genetic diversity of $P$. ramosissimus with other species in Rhamnaceae, the genetic diversity of $P$. ramosissimus was found to be higher at the population level and species level than that of endangered species such as $R$. ludovicisalvatoris, $R$. glucophylla, $R$. persicifolia, and Ziziphus celata, and endemic species such as Alphitonia ponderosa and Colubrina oppositifolia (Table 6). However, the diversity of PPB and $H$ value of $P$. ramosissimus was found to be lower than that of the widespread species $R$. alaternus at the population level and species level, and on the other hand, showed significantly higher genetic diversity than that of the widespread species Z. acidojujuba. Endangered species Berchemiella wilsonii var. pubipetiolata showed contrary genetic diversities according to the AFLP marker, a DNA-based marker, which showed lower genetic diversity, compared to allozyme, which is protein-based and showed a higher genetic diversity. Our RAPD results for the genetic diversity of $P$. ramosissimus correspond with the DNA based AFLP marker, although many plant species of Rhamnaceae exhibited different diversity according to the used marker systems.

Table 6. Comparison of genetic diversity in P. ramosissimus and literature data for other Rhamnaceae species (EN=Endangered species; $E D=$ Endemic species; $P P B=$ Percentage of

polymorphic band; He=Expected heterozygosity; I=Shannon's information index;

Pop.=population level; Sp.=species level).

\begin{tabular}{|c|c|c|c|c|c|c|c|c|c|c|c|c|}
\hline \multirow{2}{*}{ Species } & \multirow{2}{*}{ Marker } & \multirow{2}{*}{ Status } & \multicolumn{2}{|c|}{ PPB } & \multicolumn{2}{|c|}{$\mathrm{He}$} & \multicolumn{2}{|c|}{$I$} & \multirow{2}{*}{$\Phi_{\text {st }}$} & \multirow{2}{*}{ Gst } & \multirow{2}{*}{$F$ st } & \multirow{2}{*}{ References } \\
\hline & & & Pop. & Sp. & Pop. & Sp. & Pop. & Sp. & & & & \\
\hline P. ramosissimus & & & 53.8 & 78.8 & 0.218 & 0.264 & 0.316 & 0.398 & 0.207 & 0.186 & - & This study \\
\hline B. wilsonii var.pubipetiolata & AFLP & EN & 26.9 & 36.9 & 0.163 & 0.202 & - & - & 0.396 & - & - & Kang et al., 2007 \\
\hline B. wilsonii var.pubipetiolata & Allozyme & EN & 71.3 & 85.0 & 0.348 & 0.378 & - & - & - & - & 0.130 & Kang et al., 2005 \\
\hline R. persicifolia & ISSR & EN & 30.7 & 67.1 & 0.111 & 0.207 & 0.165 & 0.314 & - & 0.458 & - & Bacchetta et al., 2011 \\
\hline R. alaternus & RAPD & & 66.8 & 82.0 & 0.213 & 0.165 & - & - & - & - & - & Ferriol et al., 2009 \\
\hline R. ludovici-salvatoris & RAPD & EN & 34.6 & 69.4 & 0.045 & 0.096 & - & - & - & - & - & Ferriol et al., 2009 \\
\hline R. glucophylla & ISSR & EN & 22.6 & 48.7 & 0.080 & 0.116 & 0.119 & 0.184 & - & 0.290 & - & Bedini et al., 2011 \\
\hline Z. acidojujuba & Microsatellite & & - & - & 0.674 & 0.659 & - & 1.386 & 0.091 & 0.271 & - & Zhang et al., 2015 \\
\hline Z. celata & Allozyme & EN & - & 25.0 & - & 0.079 & - & - & - & - & - & Godt et al., 1997 \\
\hline Z. celata & Microsatellite & EN & - & - & 0.390 & - & - & - & - & - & - & $\begin{array}{l}\text { Gitzendanner et al., } \\
2012\end{array}$ \\
\hline A. ponderosa & RAPD & $\mathrm{ED}$ & 29.0 & 47.1 & 0.136 & 0.183 & - & - & 0.457 & - & - & Kwon \& Morden 2002 \\
\hline C. oppositifolia & RAPD & ED & 30.0 & 41.3 & 0.085 & 0.118 & - & - & 0.294 & - & - & Kwon \& Morden 2002 \\
\hline
\end{tabular}




\section{Genetic differentiation and gene flow among populations}

All the estimates of genetic differentiation coefficient ( $\Phi$ st and $G$ st) between populations of $P$. ramosissimus on Jeju Island revealed a low level of genetic differentiation $(20.7 \%$ and $18.6 \%$ ). Low levels of genetic differentiation among populations have previously been found in several woody species (Tetraena mongolica, Ge et al., 2003; Bretschneidera sinensis, Hu et al., 2014; Prunus mahaleb, Jordano et al., 2000; Araucaria araucana, Bekessy et al., 2002). Also, Ge et al. (2003) suggested that genetic differentiation among populations using $\Phi$ st, modified $F$-statics, and $G$ st usually exhibit below 19\% when RAPD markers have been analyzed for outcrossing plant species. These results suggest that the genetic variability of $P$. ramosissimus on Jeju Island was more attributed within population than among population, and showed similar results to referenced species in Rhamnaceae (Table 6).

Nybom (2004) surveyed the relationship of the genetic diversity index by RAPD marker within and between the populations according to the life history traits. This study found that the breeding system, life form, and seed dispersal mechanism has a great influence on the genetic diversity of the populations. According to Nybom (2004), our result of $0.207 \Phi$ st value of $P$. ramosissimus on Jeju Island is similar to that of the outcrossing plants ( $\Phi$ st value 0.27 ), while different from those of plants with selfing ( $\Phi_{\text {st }}$ value 0.65$)$ and mixed ( $\Phi_{\text {st }}$ value 0.40$)$ breeding systems. Nybom (2004) also noted that the average $\Phi$ st values of long-lived perennial and water-dispersed plants are 0.25 and 0.27 , and the average $G$ st values for these are 0.19 and 0.22 , respectively. $P$. ramosissimus on Jeju Island showed lower $\Phi$ st and $G$ st than long-lived perennial and water-dispersed plants surveyed by Nybom (2004) meaning that P. ramosissimus populations on Jeju Island have low genetic differentiation.

The gene flow $(\mathrm{Nm})$ of 1.09 of $P$. ramosissimus on Jeju Island was slightly higher than one successful migrant per generation. Wright (1931) noted that the species of $N \mathrm{~m}>1$ could be considered as genetic sameness, while those of $N \mathrm{~m}<1$ keep the differentiation of the population due to the strong differential selection. Therefore, $P$. ramosissimus has considerable gene flow among populations that could effectively homogenize genetic traits of populations to some degree (Slatkin, 1987). $P$. ramosissimus on Jeju showed relatively low $\Phi$ st and $G$ st and high gene flow, maybe affected by outcross mating system and easily dispersed seeds.

\section{Implications for conservation and the origin of P. ramosissimus on Jeju Island}

A primary objective of nature conservation is the maintenance of genetic diversity. The results of this study could be useful in the decision making process of conservation and management strategies. P. ramosissimus on Jeju Island exhibit a relatively low level of genetic differentiation among populations. Therefore, protection of $P$. ramosissimus on Jeju Island has to firstly begin with protection through in situ conservation, and prevented fragmentation and ruptures. This is because decreases in effective population size lead to stochastic events, genetic drift, and inbreeding, resulting in a decrease of genetic diversity (Hartl and Clark, 1997; Rodrigues et al., 2013). The present habitats of $P$. ramosissimus need to be protected by conservation areas and there is need to ensure dispersion because of the expected destruction of habitat and decrease of population size. Additionally, the coastal area of Jeju Island has been exposed to the pressures of development in recent times (Kim, 2006). The populations PS and IG, which have high genetic diversity, have conservation priority. In particular, PS population protection 
must the highest priority, because this population revealed high genetic diversity despite its small population size.

$P$. ramosissimus is distributed geographically in the area of southern China and Thushima, Sikoku, southern Honshu of Japan, and Jeju Island in Korea (Fig, 1; Chang, 2005; Nakanishi, 1981). These distribution areas almost harmonize with Kuroshio Warm Current, which flows from the south coast of China to the south coast of Japan through Taiwan. The Tsushima Warm Current, which is the branch of Kuroshio Warm Current, flows past Jeju Island (Cho and Choe, 1988; Pang and Kim, 1993). The hypothesis that the $P$. ramosissimus on Jeju Island and Japan originated from southern China or Taiwan may be possible in consideration of sea water flow mentioned above and the characteristic of the seed of $P$. ramosissimus, which easily float in sea water. The fact that relatively high genetic diversity of southern shore than northern shore populations probably suggests the arrival history or route of migration of $P$. ramosissimus to Jeju Island have southern origin although there is no clear evidence of this. Further molecular studies are needed to clarify the dispersion and origin of $P$. ramosissimus. Furthermore, considering the expansion of the distribution of southern plant species due to climate change, there is a possibility that this species may become established in the southern shore of the Korean peninsula. This will require attention and monitoring.

\section{REFERENCES}

[1] Bacchetta, G., Fenu, G., Mattana, E., Zecca, G., Grassi, F., Casazza, G., Minuto, L. (2011): Genetic variability of the narrow endemic Rhamnus persicifolia Moris (Rhamnaceae) and its implications for conservation. - Biochemical Systematics and Ecology 39(4): 477-484.

[2] Bedini, G., Carta, A., Zecca, G., Grassi, F., Casazza, G., Minuto, L. (2011): Genetic structure of Rhamnus glaucophylla Sommier endemic to Tuscany. - Plant Systematics and Evolution 294(3-4): 273-280.

[3] Bekessy, S. A., Allnutt, T. R., Premoli, A. C., Lara, A., Ennos, R. A., Burgman, M. A., Cortes, M., Newton, A. C. (2002): Genetic variation in the vulnerable and endemic Monkey Puzzle tree, detected using RAPDs. - Heredity 88(4): 243-249.

[4] Bolmgren, K., Oxelman, B. (2004): Generic limits in Rhamnus L. sl (Rhamnaceae) inferred from nuclear and chloroplast DNA sequence phylogenies.-Taxon 53(2): 383-383.

[5] Chang, J. S., Kim, H. (2001): The distribution of the woody plants of South Korea based on herbarium (SNUA) material of The Arboretum (VII) -Rhamnacea-. - Bulletin Of Seoul National University Arboretum 21:1-15

[6] Chang, C. S., Lee, H. S., Park, T. Y., Kim, H. (2005): Reconsideration of rare and endangered plant species in Korea based on the IUCN Red List categories. - The Korean Journal of Ecology 28(5): 305-320.

[7] Cho, K. D., Choe, Y. K. (1988): Seasonal variation of the water type in the Tsushima Current. - Korean Journal of Fisheries and Aquatic Sciences 21(6): 331-340.

[8] Ellstrand, N. C., Elam, D. R. (1993): Population genetic consequences of small population size: implications for plant conservation. - Annual review of Ecology and Systematics 217-242.

[9] Excoffier L., Laval, G., Schneider, S. (2005): Arlequin ver. 3.0: an integrated software package for population genetics data analysis. - Evolutionary bioinformatics Online 1: 47-50.

[10] Ferriol, M., Llorens, L., Gil, L., Boira, H. (2009): Influence of phenological barriers and habitat differentiation on the population genetic structure of the balearic endemic 
Rhamnus ludovici-salvatoris Chodat and $R$. alaternus L. - Plant systematics and evolution 277(1-2): 105-116.

[11] Frankham, R. (1996): Relationship of genetic variation to population size in wildlife. Conservation Biology 10: 1500-1508.

[12] Frankham, R., D. A. Briscoe, J. D. Ballou. (2002): Introduction to conservation genetics. - Cambridge University Press, Cambridge.

[13] Fritsch, P. E. T. E. R., L. H. Rieseberg. (1996): The use of random amplified polymorphic DNA (RAPD) in conservation genetics. - Molecular genetic approaches in conservation 9: 229-232.

[14] Ge, X. J., Yu, Y., Zhao, N. X., Chen, H. S., Qi, W. Q. (2003): Genetic variation in the endangered Inner Mongolia endemic shrub Tetraena mongolica Maxim.(Zygophyllaceae). - Biological Conservation 111(3): 427-434.

[15] Ge, X. J., Yu, Y., Yuan, Y. M., Huang, H. W.,Yan, C. (2005): Genetic diversity and geographic differentiation in endangered Ammopiptanthus (Leguminosae) populations in desert regions of northwest China as revealed by ISSR analysis. - Annals of Botany 95(5): 843-851.

[16] Gitzendanner, M. A., Weekley, C. W., Germain-Aubrey, C. C., Soltis, D. E., Soltis, P. S. (2012): Microsatellite evidence for high clonality and limited genetic diversity in Ziziphus celata (Rhamnaceae), an endangered, self-incompatible shrub endemic to the Lake Wales Ridge, Florida, USA. - Conservation Genetics 13(1): 223-234.

[17] Godt, M. J. W., Race, T., Hamrick, J. L. (1997): A population genetic analysis of Ziziphus celata, an endangered Florida shrub. - Journal of Heredity 88(6): 531-533.

[18] Haig, S. M. (1998): Molecular contributions to conservation. - Ecology 79(2): 413-425.

[19] Hamrick, J. L., Godt, M. J. W. (1989): Allozyme diversity in plant species. - In: Brown, A. H. D. et al. (eds.) Plant Population Genetics, Breeding and Genetic Resources. Sinauer Associates, Sunderland.

[20] Hamrick, J. L., S. Sheman-broyles. (1992): Factors influencing levels of genetic diversity in woody plant species. - In: Adams, W. et al. (eds.) Population Genetics of Forest Trees. Kuwer Academic Publishers. Netherlands.

[21] Hamrick, J. L., and Godt, M. J. W. (1996): Effects of life history traits on genetic diversity in plant species. - Philosophical Transactions of the Royal Society in Lodon, Series B 351:1291-1298.

[22] Hartl, D. L., Clark, A. G., Clark, A. G. (1997): Principles of population genetics. Sinauer associates, Sunderland.

[23] Hu, Z. Y., Lin, L., Deng, J. F., Wang, S. H. (2014): Genetic diversity and differentiation among populations of Bretschneidera sinensis (Bretschneideraceae), a narrowly distributed and endemic species in China, detected by inter-simple sequence repeat (ISSR). - Biochemical Systematics and Ecology 56: 104-110.

[24] Jordano, P., Godoy, J. A. (2000). RAPD variation and population genetic structure in Prunus mahaleb (Rosaceae), an animal-dispersed tree. - Molecular Ecology 9(9): 12931305.

[25] Kang, M., Jiang, M., Huang, H. (2005): Genetic diversity in fragmented populations of Berchemiella wilsonii var. pubipetiolata (Rhamnaceae). - Annals of botany 95(7): 11451151.

[26] Kang, M., Xu, F., Lowe, A., Huang, H. (2007): Protecting evolutionary significant units for the remnant populations of Berchemiella wilsonii var. pubipetiolata (Rhamnaceae). Conservation Genetics 8(2): 465-473.

[27] Kim, C. S. (2006): Studies on the distribution and vegetation of the endangered wild plants in Jeju Island. - Unpublished doctoral dissertation. Cheju National University, Cheju.

[28] Kim, C. S., Son, S. G., Tho, J. H., Kim, J. E., Hwang, S. I., Cheong, J. H. (2007): Distribution Characteristics of Woody Plnats resources in JeJu, Korea. - Korean Journal of Plnat Resources 20(5)424-436. 
[29] Korea National Arboretum. (2009): Rare plants data book of Korea. Korea National Arboretum, Suwon.

[30] Kwon, J. A., Morden, C. W. (2002): Population genetic structure of two rare tree species (Colubrina oppositifolia and Alphitonia ponderosa, Rhamnaceae) from Hawaiian dry and mesic forests using random amplified polymorphic DNA markers. - Molecular Ecology 11(6): 991-1001.

[31] Lee, T. B. (2003): Illustrated Flora of Korea.-Hyang-mun Pub. Co., Seoul.

[32] Li, X., Li, S., Chu, H., Li, Z., Chen, Y. (2013): Genetic diversity and population structure of the endangered alpine quillwort Isoetes hypsophila (Isoetaceae) revealed by SSR analysis. - Biochemical Systematics and Ecology 47: 11-20.

[33] Liu, Z., Shu, Q., Wang, L., Yu, M., Hu, Y., Zhang, H., Tao, Y., Shao, Y. (2012): Genetic diversity of the endangered and medically important Lycium ruthenicum Murr. revealed by sequence-related amplified polymorphism (SRAP) markers. - Biochemical Systematics and Ecology 45: 86-97.

[34] Medan, D. (1994). Reproductive biology of Frangula alnus (Rhamnaceae) in southern Spain. - Plant Systematics and Evolution 193(1-4): 173-186.

[35] Medan, D., Basilio, A. M. (2001): Reproductive biology of Colletia spinosissima (Rhamnaceae) in Argentina. - Plant Systematics and Evolution 229(1-2): 79-89.

[36] Milligan, B. G., Leebens, J. Mack, A. E. Strand. (1994): Conservation genetics: beyond the maintenance of marker diversity. - Molecular Ecology 3(4): 423-435.

[37] Ministry of Environment. (2005): A picture guidebook on endangered wild animals and plants.

[38] Ministry of Environment. (2012): Natural Environment Conservation Act. Available from <http://www.me.go.kr>.

[39] Nakanishi, H. (1981): Distribution and ecology of Paliurus ramosissimus community. Acta phytotaxonomica et geobotanica. - 32:105-113.

[40] Nakanishi, H., Kim, H., M., Kim, C. S. (2004): Distribution and ecology of Hibiscus hamabo and Paliurus ramosissimus in Jeju Island, Korea. - Bulletin-Facylty of Education Nagasaki University Natural Science 1-10.

[41] Nei, N. (1978): Estimation of average heterozygosity and genetic distance from a small number of individuals. - Genetics 89: 583-590

[42] Newton, A. C., Allnutt, T. R., Gillies, A. C. M., Lowe, A. J., Ennos, R. A. (1999): Molecular phylogeography, intraspecific variation and the conservation of tree species. Trends in Ecology \& Evolution 14(4): 140-145.

[43] Nybom, H. (2004): Comparison of different nuclear DNA markers for estimating intraspecific genetic diversity in plants. - Molecular ecology 13(5): 1143-1155.

[44] Pang, I. C., Kim, T. H. (1993): Upwelling in the western sea of the Cheju Island. Bulletin Marine Research Institute Cheju National University 17:1-12.

[45] Peakall, R. O. D., Smouse, P. E. (2006): GENALEX 6: genetic analysis in Excel. Population genetic software for teaching and research. - Molecular ecology notes 6(1): 288-295.

[46] Rodrigues, L., van den Berg, C., Póvoa, O., Monteiro, A. (2013): Low genetic diversity and significant structuring in the endangered Mentha cervina populations and its implications for conservation. - Biochemical Systematics and Ecology 50: 51-61.

[47] Slatkin, M. (1987): Gene flow and the geographic structure of natural populations. Science 236(4803): 787-792.

[48] Slatkin, M., Barton, N. H. (1989): A comparison of three indirect methods for estimating average levels of gene flow. - Evolution 43(7): 1349-1368.

[49] Tansley, S. A. and C. R. Brown (2000): RAPD variation in the rare and endagered Leucadendron elimense(Proteaceae): implications for their conservation - Biological conservation 95(1): 39-48

[50] Trindade, H., Costa, M. M., Lima, S. B., Pedro, L. G., Figueiredo, A. C., Barroso, J. G. (2009): A combined approach using RAPD, ISSR and volatile analysis for the 
characterization of Thymus caespititius from Flores, Corvo and Graciosa islands (Azores, Portugal). - Biochemical Systematics and Ecology 37(5):670-677.

[51] Wright, S. (1931): Evolution in Medelian population. - Genetics 16: 97-159.

[52] Yeh, F. C., Yang, R. C., \& Boyle, T. (1997). Population genetic analysis (POPGENE, Version 1.32). Department of Renewable Resources, University of Alberta, Edmonton.

[53] Yu, H. H., Z. L. Yang, B. Sun, R. N. Liu. (2011): Genetic diversity and relationship of endangered plant Magnolia officinalis (Magnoliaceae) assessed with ISSR polymorphisms. - Biochemical Systematics and Ecology 39(2): 71-78.

[54] Zhang, C., Huang, J., Yin, X., Lian, C., Li, X. (2015): Genetic diversity and population structure of sour jujube, Ziziphus acidojujuba. - Tree genetics \& genomes 11(1): 1-12.

[55] Zhang, R., Z. Zhou, K. Du. (2012): Genetic diversity of natural populations of endangered Ormosia hosiei, endemic to China. - Biochemical Systematics and Ecology 40: 13-18. 